Dementia

and Geriatric

Cognitive Disorders
Dement Geriatr Cogn Disord 2014;38:286-299

DOI: 10.1159/000362926

Accepted: April, 15, 2014

Published online: July 3, 2014

\title{
Risk Factors That Affect Life \\ Expectancy in Alzheimer's Disease: A 15-Year Follow-Up
}

\author{
Carina Wattmo Elisabet Londos Lennart Minthon \\ Clinical Memory Research Unit, Department of Clinical Sciences, Malmö, Lund University, \\ Malmö, Sweden
}

\section{Key Words}

Cholinesterase inhibitors · Apolipoprotein E genotype · Level of education · Mortality · Longitudinal study

\begin{abstract}
Backgrounds/Aims: Future disease-modifying therapies might affect the expected life span in Alzheimer's disease (AD). Our aim was to identify factors that influence life expectancy in cholinesterase inhibitor (ChEI)-treated patients. Methods: This study included 791 deceased individuals with a clinical diagnosis of AD and a Mini-Mental State Examination score of 10-26 at baseline who were recruited from a 3-year, prospective, multicenter study of ChEI therapy in clinical practice. The participants' date of death was recorded and their survival was compared with the gender- and age-matched general population. Results: The mean survival time after the start of ChEI therapy (time of AD diagnosis) was 5.10 years for men and 6.12 years for women. Better cognitive ability, less impaired basic functional capacity, and fewer medications, but not education level or apolipoprotein E (APOE) genotype, were independent prognostic factors of longer survival after diagnosis, after controlling for gender and age. Conclusion: AD shortens life expectancy in ChEI-treated patients diagnosed before the age of 85 years, similar to that reported previously for untreated individuals. A longer life span was observed in the eldest patients ( $\geq 85$ years) compared with untreated cohorts, which did not differ from that observed in the general population. Higher education or carrying two APOE $\varepsilon 4$ alleles were risk factors for earlier death.

(C) 2014 S. Karger AG, Basel
\end{abstract}




\section{Introduction}

Alzheimer's disease (AD) will be one of the greatest future global health care challenges. Aging is the dominant risk factor for the development of $\mathrm{AD}$, and the increasing life expectancy of humans is the most important reason for the rising AD prevalence rates observed in both developed and developing countries [1]. In 2010, an estimated 36 million individuals had $\mathrm{AD}$ and other dementias worldwide; this number will reach 66 million by the year 2030, and 115 million by 2050 [2]. In addition to the suffering of the individuals affected with $\mathrm{AD}$ and their families, the societal costs are enormous. In the year 2010, the cost of dementia was USD 604 billion, which is equal to $1 \%$ of the global gross domestic product [3].

$\mathrm{AD}$ is the most common dementia disorder [4] and is characterized by a progressive and irreversible deterioration of cognitive and functional abilities that leads to major difficulties to manage independently after only a few years of disease duration [5]. Survival from the time of $\mathrm{AD}$ diagnosis has been reported to vary between 3 and 10 years, mainly depending on the patient's age [6,7]. By comparison, the average 75-year old person in Sweden has a life expectancy of 12 years [8].

Whether the predominant symptomatic pharmaceutical treatment for $\mathrm{AD}$, administration of cholinesterase inhibitors (ChEIs), alters the length of life is not clear. Few earlier studies have compared the life span in AD patients receiving ChEIs with untreated cohorts and observed conflicting results regarding life prolongation $[9,10]$. In addition, comparisons of survival in AD with life expectancy in the general population and reports of potential differences in the length of life according to AD stage are scarce [11].

Several genetic, demographic, and disease-related factors have been reported to increase the risk of mortality in $\mathrm{AD}$, such as male gender $[10,12,13]$, older age at baseline $[6,7,10,13$, 14], a higher level of education [15], the presence of the apolipoprotein E (APOE) $\varepsilon 4$ allele [16], younger age at onset [12], lower cognitive status [13,14,17], and comorbid medical disorders [13].

However, other studies showed that the above-mentioned variables had no effect on life span: gender $[6,7,14,17]$, age at baseline [17], level of education $[6,7,10,13]$, APOE genotype $[7,14]$, age at onset [14], cognitive severity [10], and comorbidity [10].

An increased understanding of the factors that might affect the life span in AD patients treated with ChEIs is important for clinicians to estimate patient prognosis and for communitybased services for the planning of care and allocation of resources. Moreover, detailed information regarding life expectancy in AD might be a valuable tool for the health authorities to evaluate the effects and the costs of the disease from a societal perspective.

The aims of this study were (1) to compare the life span of ChEI-treated AD patients with that of untreated cohorts and with the life expectancy in the general population, and (2) to examine the influence of factors such as years of education, number of APOE $\varepsilon 4$ alleles, age at onset, and cognitive severity on mortality.

\section{Materials and Methods}

Study and Subjects

The Swedish Alzheimer Treatment Study (SATS) was started in August 1997 to investigate the longterm effectiveness of ChEI therapy (donepezil, rivastigmine, and galantamine) in AD patients in a routine clinical setting. The SATS is a prospective, open-label, observational, nonrandomized, multicenter study that has been described in several publications [18-21]. In total, 1,258 participants were recruited until April 2008 by 14 memory clinics that cover different parts of Sweden. At the start of ChEI treatment (baseline), 1,021 of the patients had mild-to-moderate AD with Mini-Mental State Examination (MMSE) scores [22] 
Wattmo et al.: Risk Factors That Affect Life Expectancy in Alzheimer's Disease: A 15-Year Follow-Up

ranging from 10 to 26. Among these, 791 individuals (77\%) had died by December 31, 2012, and were included in the present study.

The SATS participants fulfilled the clinical criteria of dementia, as defined by the Diagnostic and Statistical Manual of Mental Disorders, 4th edition (DSM-IV) [23], and of probable or possible AD, according to the criteria of the National Institute of Neurological and Communicative Disorders and Stroke and the Alzheimer's Disease and Related Disorders Association (NINCDS-ADRDA) [24]. The inclusion criteria were wide and included age $>40$ years, living in their own home at the time of diagnosis, having a responsible caregiver/ informant, and assessability with the MMSE at baseline. Patients who did not fulfill the diagnostic criteria for $\mathrm{AD}$ and those already on active treatment with any ChEI or with contraindications for these drugs were excluded from the study. Medication other than ChEI was allowed during the study. However, if another dementia treatment (i.e., memantine or study drugs) was added, the patient left the study at that point.

The study was approved by the Ethics Committee of the Lund University, Lund, Sweden. All patients and their closest relative/caregiver provided written informed consent to participate in the study, which was carried out in accordance with the Helsinki Declaration.

\section{Study Design and Outcome Measures}

The SATS patients were assessed in a well-structured follow-up program, which investigated cognitive status, global performance, and functional ability at the start of ChEI treatment, after 2 months (MMSE and global rating only), and semiannually for a period of 3 years. The inclusion in the SATS and the evaluations at baseline were performed immediately after AD diagnosis, followed by the initiation of ChEI therapy according to the approved product recommendations. The choice of drug agent and dose was left entirely to the physician's (specialist in dementia disorders) discretion and professional judgment.

The age at onset of AD was estimated by the clinician based on an interview with the patient's caregiver. Early onset was defined as an onset before 65 years of age. Cognitive assessment was performed using the MMSE, with scores ranging from 0 to 30, and a higher score indicating better function. At the start of ChEI treatment, 538 individuals (68\%) were defined as having mild (MMSE score, 20-26) and 253 (32\%) were defined as having moderate (MMSE score, 10-19) AD.

The capacity to perform daily activities was assessed using the Instrumental Activities of Daily Living (IADL) scale [25], which consists of eight items: telephone usage, shopping, food preparation, housekeeping, doing laundry, mode of transportation, responsibility for own medications, and handling finances. Each item was scored from 1 (no impairment) to 3-5 (severe impairment), thus allowing a total range of 8-31 points. The Physical Self-Maintenance Scale (PSMS) [25] consists of six items: toilet, feeding, dressing, grooming, physical ambulation, and bathing. Each item was scored from 1 (no impairment) to 5 (severe impairment), thus allowing a total range of 6-30 points.

\section{Mortality and Life Expectancy}

Using the 12-digit personal identity number assigned to each resident in Sweden, all 1,258 SATS patients were investigated with the help of the Swedish population register (Swedish Tax Agency) regarding whether they were still alive on December 31, 2012. If not, the date of death was recorded.

The probable remaining length of life for each participant according to their gender and age at baseline was obtained from Statistics Sweden, based on life tables for the periods of 1993-1997 [26], 1998-2002 [27], 2003-2007 [28], and 2008-2012 [8], depending on the individual's year of inclusion in the SATS. The patient's actual survival time was compared with his/her expected life span relative to the gender- and agematched general population. This unique approach allows the estimation of the decrease in the mean number of years of life span in association with different risk factors such as age at diagnosis, APOE genotype, and stages of $\mathrm{AD}$.

\section{Statistical Analyses}

The IBM Statistical Package for the Social Sciences (SPSS) software (version 21.0; IBM Corporation, Armonk, N.Y., USA) was used to perform the statistical analyses. The level of significance was defined as $\mathrm{p}<$ 0.05 if not otherwise specified. Histograms were generated to assess the distribution of the continuous variables, and skewness was calculated as a measure of symmetry. The skewness was $<1.0$ or $>-1.0$ in all continuous variables; thus, the distribution was regarded as approximately symmetrical. Parametric tests were used because of the approximately normally distributed variables and the large sample size. One-way analysis of variance (ANOVA) was used to compare the differences between the means obtained for the three independent groups, a t test was performed to analyze two independent groups, and a $\chi^{2}$ test was used to 
Dementia

Cognitive Disorders

Table 1. Patient characteristics (n= 791)

\begin{tabular}{l|l}
\hline \multicolumn{2}{l}{ Dement Geriatr Cogn Disord 2014;38:286-299 } \\
\hline DOI: $10.1159 / 000362926$ & $\begin{array}{l}\text { @ 2014 S. Karger AG, Basel } \\
\text { www.karger.com/dem }\end{array}$ \\
\hline
\end{tabular}

Wattmo et al.: Risk Factors That Affect Life Expectancy in Alzheimer's Disease: A 15-Year Follow-Up
Female gender

APOE \&4 noncarrier

APOE, carrier of one $\varepsilon 4$ allele

APOE, carrier of two $\varepsilon 4$ alleles

Antihypertensives/cardiac therapy at baseline

Estimated age at onset, years

Estimated duration of $\mathrm{AD}$ at baseline, years

Age at first assessment, years

Education, years

Age at death, years

MMSE score at baseline

IADL score at baseline

PSMS score at baseline

Concomitant medications at baseline, $n$

Length in the SATS, months
$490(62)$

$265(34)$

$399(52)$

108 (14)

331 (42)

$73.0 \pm 6.8$

$3.1 \pm 2.0$

$76.1 \pm 6.4$

$9.4 \pm 2.5$

$81.8 \pm 6.5$

$21.0 \pm 3.8$

$16.7 \pm 5.4$

$7.7 \pm 2.4$

$3.1 \pm 2.5$

$22.3 \pm 13.0$

Values are $\mathrm{n}(\%)$ or mean $+\mathrm{SD}$.

analyze categorical variables. A paired t test was used to compare the differences between the means for two related samples.

Cox proportional hazards models with backward stepwise elimination were used to estimate separately the effects of different risk factors [gender, age at start of ChEI treatment, years of education, number of APOE $\varepsilon 4$ alleles, age at onset of AD, MMSE, IADL and PSMS scores, number of concomitant medications and antihypertensives/cardiac therapy (no/yes) at baseline] on the relative risk of time to death. Univariate Cox regression analyses were performed with adjustment for the potentially confounding baseline demographic variables of gender and age. A multivariate Cox model was then used to estimate simultaneously the effects of all the above-mentioned risk factors on the time to death. Variables with $p>0.05$ were removed from the stepwise models. No violation of the assumption of proportional hazards was detected.

\section{Results}

\section{Patient Characteristics}

The sociodemographic and clinical characteristics of the 791 deceased AD patients are listed in table 1 . Males had significantly more years of education [mean \pm standard deviation (SD), $9.8 \pm 2.9$ vs. $9.1 \pm 2.2$ years, $\mathrm{t}(788)=3.75$, $\mathrm{p}<0.001]$ and a lower frequency of the APOE $\varepsilon 4$ allele [ 59 vs. $\left.70 \%, \chi^{2}(1)=7.90, p=0.005\right]$ compared with females. No gender-based differences in age at onset, age at baseline, and cognitive ability were observed. Age at onset and age at baseline did not differ between the mild (MMSE score, 20-26) and moderate (MMSE score, 10-19) AD cohorts.

The group with a higher level of education ( $>9$ years) was younger at the onset of AD $[71.4 \pm 7.4$ vs. $73.5 \pm 6.6$ years, $\mathrm{t}(787)=3.55, \mathrm{p}<0.001]$ and at the start of ChEI treatment $[74.6 \pm 7.1$ vs. $76.5 \pm 6.1$ years, $\mathrm{t}(788)=3.31, \mathrm{p}=0.001]$, and had a higher MMSE score at baseline [ $22.0 \pm 3.5$ vs. $20.7 \pm 3.9$ points, $\mathrm{t}(788)=-4.00, \mathrm{p}<0.001]$.

Individuals carrying two APOE $\varepsilon 4$ alleles were significantly younger at the onset of AD $(70.0 \pm 6.7$ years $)$ than were those carrying one $\varepsilon 4$ allele $(72.9 \pm 6.8$ years $)$ and the noncarriers $[74.1 \pm 6.7$ years, $F(2,768)=13.65, p<0.001]$. The group with two APOE $\varepsilon 4$ alleles was also younger at the start of ChEI therapy (73.6 \pm 6.1 years) compared with carriers of one $\varepsilon 4$ allele $(76.0 \pm 6.4$ years $)$ and noncarriers $[77.0 \pm 6.3$ years, $F(2,769)=10.66, p<0.001]$. No differences in years of education and cognitive status at baseline were found among patients with various APOE genotypes. 
Wattmo et al.: Risk Factors That Affect Life Expectancy in Alzheimer's Disease: A 15-Year Follow-Up

Table 2. Age at death for different AD cohorts by gender

\begin{tabular}{lccc}
\hline Variable & $\begin{array}{l}\text { Number of } \\
\text { males/females }\end{array}$ & Males & Females \\
& $20 / 23$ & $66.0(63.8-68.2)$ & $66.8(64.9-68.8)$ \\
$\leq 64$ years at baseline & $21 / 43$ & $72.9(71.9-73.8)$ & $74.3(73.3-75.3)$ \\
$65-69$ years at baseline & $74 / 96$ & $78.2(77.4-78.9)$ & $78.6(77.9-79.2)$ \\
$70-74$ years at baseline & $97 / 172$ & $82.2(81.6-82.8)$ & $83.3(82.8-83.7)$ \\
$75-79$ years at baseline & $68 / 123$ & $85.7(85.1-86.3)$ & $87.6(87.1-88.1)$ \\
$80-84$ years at baseline & $21 / 33$ & $90.7(89.7-91.7)$ & $91.3(90.4-92.2)$ \\
$\geq 85$ years at baseline & $216 / 390$ & $81.2(80.3-82.1)$ & $83.0(82.4-83.6)$ \\
Level of education $\leq 9$ years & $85 / 99$ & $80.1(78.6-81.5)$ & $80.0(78.4-81.5)$ \\
Level of education >9 years & $118 / 147$ & $81.8(80.7-82.9)$ & $83.4(82.3-84.5)$ \\
APOE $\varepsilon 4$ noncarrier & $137 / 262$ & $80.1(78.9-81.2)$ & $82.6(81.8-83.4)$ \\
APOE, carrier of one $\varepsilon 4$ allele & $35 / 73$ & $79.4(77.5-81.4)$ & $80.2(78.7-81.6)$ \\
APOE, carrier of two $\varepsilon 4$ alleles & $37 / 45$ & $69.3(67.5-71.0)$ & $70.5(68.8-72.3)$ \\
Early-onset AD (<65 years) & $264 / 443$ & $82.5(81.9-83.1)$ & $83.6(83.1-84.1)$ \\
Late-onset AD ( $\geq 65$ years) & $203 / 335$ & $81.6(80.8-82.4)$ & $82.5(81.8-83.2)$ \\
Mild AD (MMSE score, 20-26) & $98 / 155$ & $79.3(77.9-80.8)$ & $82.3(81.2-83.3)$ \\
Moderate AD (MMSE score, 10-19) & & &
\end{tabular}

Values are means with 95\% CI in parentheses, except where otherwise indicated. Baseline indicates the start of ChEI therapy shortly after AD diagnosis.

The number of individuals treated with donepezil, rivastigmine, and galantamine was 466 (59\%), 164 (21\%), and 161 (20\%), respectively. During the SATS, the mean ChEI \pm SD doses were $6.8 \pm 1.8 \mathrm{mg}$ of donepezil, $6.0 \pm 2.1 \mathrm{mg}$ of rivastigmine, and $14.9 \pm 3.8 \mathrm{mg}$ of galantamine. No significant difference in the dose was detected according to gender, education level, APOE genotype, or stage of AD.

\section{Age at Death}

Female AD patients exhibited a longer life span compared with males [mean, 82.4 years (95\% confidence interval, CI, 81.8-83.0) vs. 80.9 years (95\% CI 80.1-81.6), t $(789)=-3.26$, $\mathrm{p}=0.001$ ]. Table 2 shows the mean age at death (with 95\% CIs) for the male and female cohorts divided into 5-year age groups at the start of ChEI therapy, low ( $\leq 9$ years) versus high ( $>9$ years) level of education, APOE genotype, early versus late onset of AD, and mild versus moderate stage.

Individuals with AD having a higher education level died at a younger age than those with a lower education level [mean, 80.0 years (95\% CI 79.0-81.1) vs. 82.4 years (95\% CI 81.982.9), $\mathrm{t}(788)=4.04, \mathrm{p}<0.001]$. Carriers of two APOE $\varepsilon 4$ alleles were significantly younger at death [mean, 79.9 years (95\% CI 78.8-81.0)] compared with carriers of one $\varepsilon 4$ allele [mean, 81.7 years (95\% CI 81.1-82.4)] and noncarriers [mean, 82.7 years (95\% CI 81.9-83.5), F(2, $769)=6.92, p=0.001]$. Patients with an early onset of $\mathrm{AD}(<65$ years $)$ died at a younger age than those with late-onset $\mathrm{AD}$ [mean, 70.0 years $(95 \% \mathrm{CI} 68.8-71.2)$ vs. 83.2 years $(95 \% \mathrm{CI}$ 82.8-83.6), $\mathrm{t}(787)=-22.10, \mathrm{p}<0.001]$. The individuals in the mild stage of AD were older at death [mean, 82.2 years (95\% CI 81.6-82.7)] compared with those in the moderate stage [mean, 81.1 years (95\% CI 80.3-82.0), t(789) $=2.10, \mathrm{p}=0.036$ ].

\section{Life Expectancy in AD Compared with the General Population}

The mean survival time after the estimated onset of AD symptoms was 8.83 years $(95 \%$ CI 8.58-9.07) and was shorter in males [8.20 years (95\% CI 7.82-8.57)] than in females [9.22 
Dementia

Cognitive Disorders

\begin{tabular}{l|l}
\hline \multicolumn{2}{l|}{ Dement Geriatr Cogn Disord 2014;38:286-299 } \\
\hline DOI: $10.1159 / 000362926$ & $\begin{array}{l}\text { C 2014 S. Karger AG, Basel } \\
\text { www.karger.com/dem }\end{array}$ \\
\hline
\end{tabular}

Wattmo et al.: Risk Factors That Affect Life Expectancy in Alzheimer's Disease: A 15-Year Follow-Up

Table 3. Life expectancy (years) after the start of ChEI therapy in AD compared with the gender- and age-matched general population

\begin{tabular}{|c|c|c|c|c|c|c|}
\hline \multirow[t]{2}{*}{ Variable } & \multicolumn{3}{|l|}{ Males } & \multicolumn{3}{|l|}{ Females } \\
\hline & $\mathrm{AD}$ & $\begin{array}{l}\text { general } \\
\text { population }\end{array}$ & $\begin{array}{l}\text { differ- } \\
\text { ence }^{a}\end{array}$ & $\mathrm{AD}$ & $\begin{array}{l}\text { general } \\
\text { population }\end{array}$ & $\begin{array}{l}\text { differ- } \\
\text { ence }^{a}\end{array}$ \\
\hline$\leq 64$ years at baseline & $6.35(5.28-7.41)$ & $21.30(19.57-23.03)$ & -14.95 & $7.30(6.10-8.50)$ & $24.88(23.55-26.21)$ & -17.58 \\
\hline $65-69$ years at baseline & $5.77(4.77-6.76)$ & $15.32(14.74-15.90)$ & -9.55 & $6.66(5.74-7.59)$ & $18.06(17.73-18.40)$ & -11.40 \\
\hline $70-74$ years at baseline & $5.62(4.96-6.28)$ & $11.52(11.29-11.74)$ & -5.90 & $6.40(5.79-7.02)$ & $14.40(14.17-14.62)$ & -8.00 \\
\hline $75-79$ years at baseline & $4.91(4.39-5.44)$ & $8.66(8.50-8.81)$ & -3.75 & $5.97(5.56-6.37)$ & $10.68(10.54-10.82)$ & -4.71 \\
\hline $80-84$ years at baseline & $4.19(3.70-4.68)$ & $6.47(6.32-6.63)$ & -2.28 & $5.98(5.49-6.48)$ & $8.04(7.90-8.18)$ & -2.06 \\
\hline$\geq 85$ years at baseline & $5.28(4.33-6.22)$ & $4.84(4.71-4.97)$ & 0.44 & $5.11(4.26-5.97)$ & $5.75(5.59-5.91)$ & -0.64 \\
\hline Level of education $\leq 9$ years & $5.12(4.78-5.46)$ & $9.72(9.16-10.27)$ & -4.60 & $6.24(5.96-6.52)$ & $11.35(10.94-11.76)$ & -5.11 \\
\hline Level of education $>9$ years & $5.06(4.49-5.63)$ & $10.39(9.43-11.35)$ & -5.33 & $5.68(5.13-6.23)$ & $13.24(12.11-14.36)$ & -7.56 \\
\hline APOE $\varepsilon 4$ noncarrier & $5.40(4.92-5.87)$ & $9.52(8.85-10.18)$ & -4.12 & $5.90(5.41-6.38)$ & $10.95(10.18-11.72)$ & -5.05 \\
\hline APOE, carrier of one $\varepsilon 4$ allele & $4.81(4.40-5.22)$ & $10.23(9.45-11.02)$ & -5.42 & $6.25(5.92-6.57)$ & $11.69(11.16-12.22)$ & -5.44 \\
\hline APOE, carrier of two $\varepsilon 4$ alleles & $5.73(4.84-6.62)$ & $11.10(9.64-12.56)$ & -5.37 & $6.49(5.83-7.16)$ & $13.54(12.49-14.59)$ & -7.05 \\
\hline Late-onset $\mathrm{AD}$ ( $\geq 65$ years) & $4.95(4.64-5.26)$ & $8.70(8.40-9.00)$ & -3.75 & $6.05(5.79-6.32)$ & $10.77(10.47-11.07)$ & -4.72 \\
\hline Mild AD (MMSE score, 20-26) & $5.31(4.95-5.67)$ & $9.53(9.02-10.04)$ & -4.22 & $6.31(5.99-6.62)$ & $11.79(11.30-12.27)$ & -5.48 \\
\hline Moderate AD (MMSE score, 10-19) & $4.67(4.22-5.13)$ & $10.68(9.65-11.71)$ & -6.01 & $5.73(5.34-6.12)$ & $11.60(10.88-12.32)$ & -5.87 \\
\hline
\end{tabular}

Values are means with $95 \% \mathrm{CI}$ in parentheses.

a All differences were significant at $\mathrm{p}<0.001$, except for the $\geq 85$ years group's survival time, which did not differ between the AD patients and the general population. Baseline indicates the start of ChEI therapy shortly after AD diagnosis.

years $(95 \% \mathrm{CI} 8.90-9.53), \mathrm{t}(787)=-4.11, \mathrm{p}<0.001]$. The mean time after the start of ChEI treatment to death was 5.73 years (95\% CI 5.54-5.93), and was also significantly shorter in males [5.10 years (95\% CI 4.82-5.39)] compared with females [6.12 years (95\% CI 5.876.37), $\mathrm{t}(789)=-5.27, \mathrm{p}<0.001]$. Table 3 shows the mean length of life (with $95 \%$ CIs) for the male and female SATS cohorts divided into 5-year age groups at the start of ChEI therapy, low versus high level of education, APOE genotype, early versus late onset of AD, and mild versus moderate stage. Life expectancy for the gender- and age-matched general population is also presented, together with the AD patients' estimated decrease in length of life for each cohort.

There was a trend towards significance $(\mathrm{p}=0.052)$ for participants with a lower education level to have a longer survival time after baseline [mean, 5.84 years (95\% CI 5.62-6.06) vs. 5.39 years (95\% CI 5.00-5.79)] compared with individuals with a higher education level. Patients with an early onset of AD showed a longer time from the baseline to death than those with late-onset AD [mean, 6.55 years (95\% CI 5.97-7.13) vs. 5.64 years (95\% CI 5.44-5.85), $\mathrm{t}(787)=2.83, \mathrm{p}=0.005]$. The individuals in the mild stage of $\mathrm{AD}$ had a longer survival time compared with those in the moderate stage [mean, 5.93 years (95\% CI 5.69-6.17) vs. 5.32 years (95\% CI 5.02-5.62), $t(789)=3.09, p=0.002]$. No significant difference in length of life from the start of ChEI treatment was observed among the APOE genotypes.

Figure 1a-d illustrates the age of the SATS participants at onset of AD, age at time of diagnosis, age at death and expected loss of years to $\mathrm{AD}$, on average, according to a low versus high level of education, APOE genotype, early versus late onset of $\mathrm{AD}$, and mild versus moderate stage.

Life Expectancy in ChEI-Treated AD Patients Compared with Historical Untreated Cohorts

The mean survival time in the ChEI-treated SATS participants was 6.3 years for patients $<75$ years, 5.5 years for those aged $75-84$ years, and 5.2 years for those aged $\geq 85$ years at AD diagnosis. Brookmeyer et al. [6] reported a median life expectancy of 6.0 years for untreated individuals $<75$ years, 5.0 years for those aged 75-84 years, and 3.5 years for those aged $\geq 85$ 


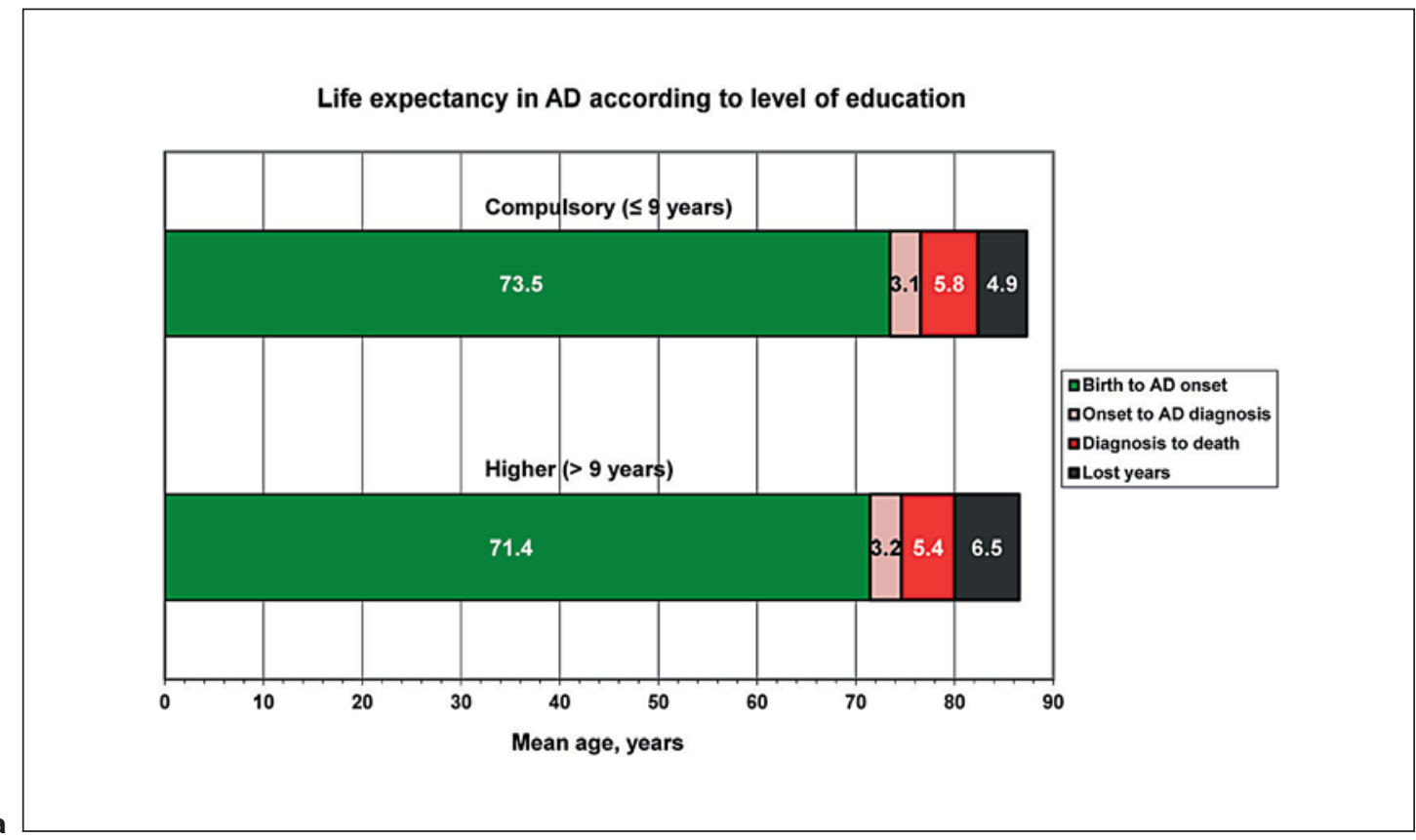

Life expectancy in AD according to APOE genotype

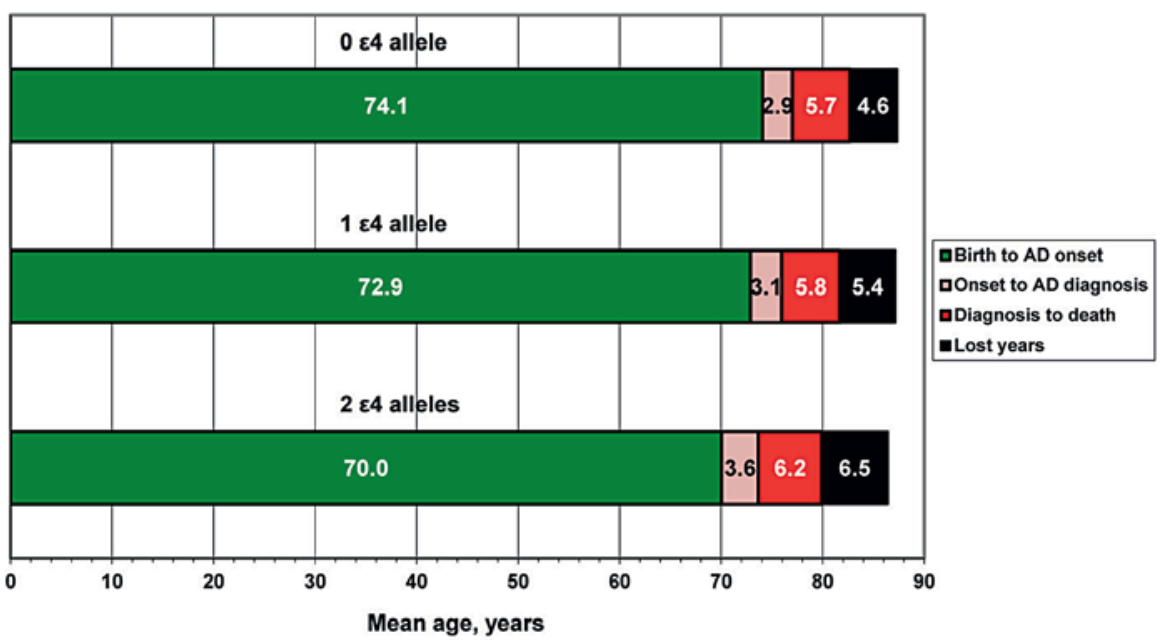

b

Fig. 1. a Mean age at $A D$ onset, age at diagnosis, age at death and lost years to $A D$ compared with the general population according to a low versus high level of education. The patients with a higher level of education were younger at the onset of $\mathrm{AD}(\mathrm{p}<0.001)$ and at the time of diagnosis $(\mathrm{p}=0.001)$, died at a younger age $(p<0.001)$ and lost on average 1.5 more years to the disease $(p<0.001)$ than those with a lower education. b Mean age at $\mathrm{AD}$ onset, age at diagnosis, age at death and lost years to $\mathrm{AD}$ compared with the general population according to APOE genotype. The carriers of two APOE $\varepsilon 4$ alleles were younger at the onset of AD $(\mathrm{p}<0.001)$, at the time of diagnosis $(\mathrm{p}<0.001)$ and at death $(\mathrm{p}=0.001)$ compared with carriers of one $\varepsilon 4$ allele and noncarriers. The carriers of two $\varepsilon 4$ alleles lost a mean of approximately 2 additional years to $A D$ compared with the noncarriers $(\mathrm{p}=0.002)$. 

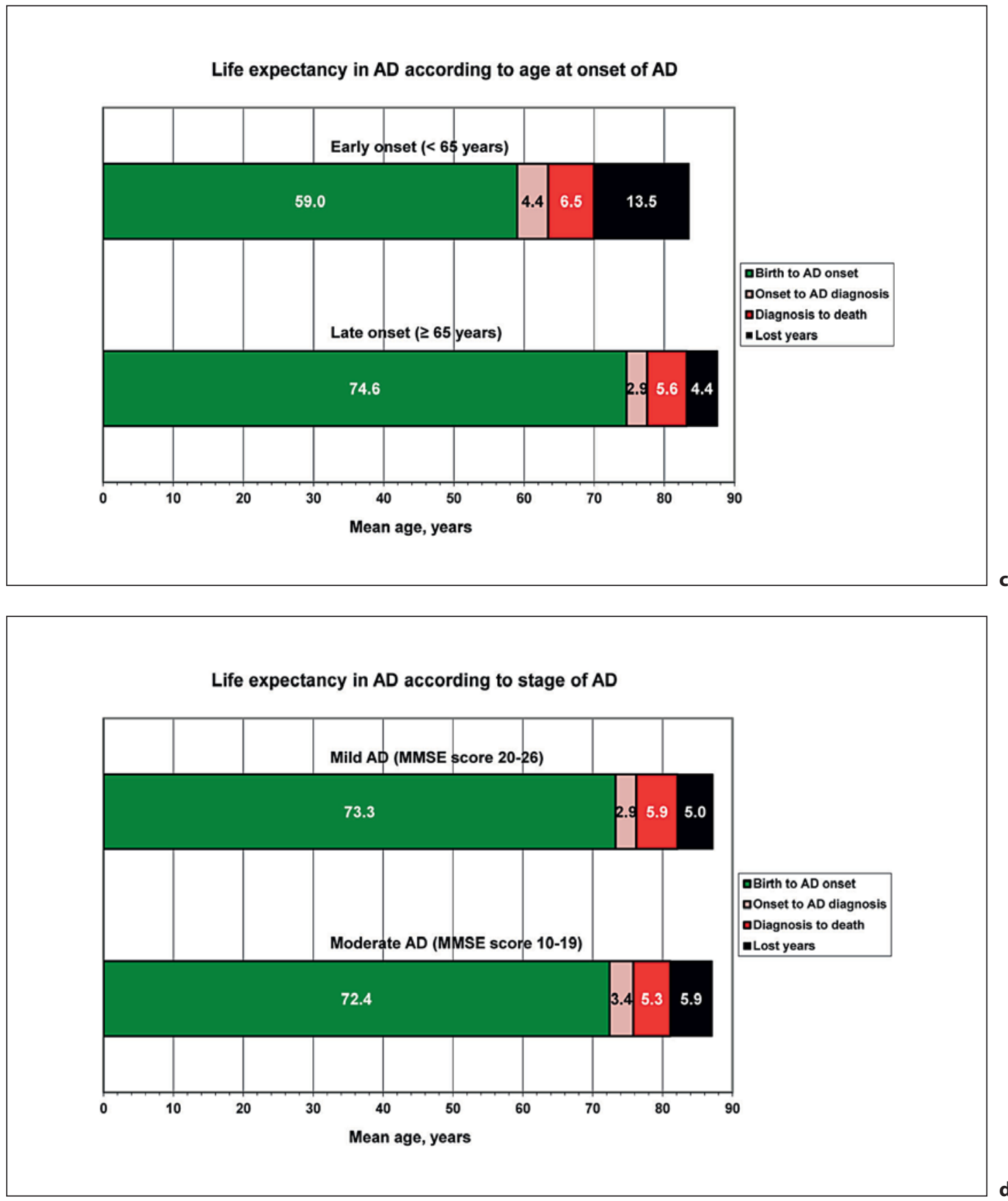

Fig. 1. c Mean age at $\mathrm{AD}$ onset, age at diagnosis, age at death and lost years to $\mathrm{AD}$ compared with the general population according to early versus late onset of AD. Patients with an early onset of AD died at a younger age $(p<0.001)$ and lost more years to the disease $(p<0.001)$, but exhibited a longer time from AD onset to diagnosis $(p<0.001)$ and from AD diagnosis to death $(p=0.005)$ than the individuals with late-onset disease. d Mean age at AD onset, age at diagnosis, age at death and lost years to AD compared with the general population according to mild versus moderate disease stage. The patients in the mild stage of AD exhibited a shorter time from AD onset to diagnosis ( $p=0.007)$, were older at death $(p=0.036)$, had a longer survival time after AD diagnosis $(p=0.002)$ and lost on average 1 year less to the disease $(p=0.012)$ compared with those in the moderate stage. 


\section{Dementia}

Cognitive Disorders
C 2014 S. Karger AG, Basel www.karger.com/dem

Wattmo et al.: Risk Factors That Affect Life Expectancy in Alzheimer's Disease: A 15-Year Follow-Up

Table 4. Cox proportional hazards modeling of time to death

\begin{tabular}{|c|c|c|c|c|}
\hline & \multicolumn{2}{|l|}{ Univariate $^{\mathrm{a}}$} & \multicolumn{2}{|c|}{ Multivariate, significant predictors } \\
\hline & hazard ratio $(95 \% \mathrm{CI})$ & $\mathrm{p}$ value & hazard ratio $(95 \% \mathrm{CI})$ & $\mathrm{p}$ value \\
\hline Gender $($ male $=0$, female $=1)$ & $0.66(0.57-0.76)$ & $<0.001$ & $0.62(0.54-0.72)$ & $<0.001$ \\
\hline Age at baseline (years) & $1.03(1.02-1.04)$ & $<0.001$ & $1.02(1.01-1.04)$ & $<0.001$ \\
\hline Education (years) & $1.02(0.99-1.05)$ & 0.158 & & \\
\hline Number of APOE $\varepsilon 4$ alleles & $1.02(0.91-1.13)$ & 0.746 & & \\
\hline Estimated age at onset (years) & $1.00(0.97-1.04)$ & 0.804 & & \\
\hline MMSE score at baseline & $0.96(0.94-0.98)$ & $<0.001$ & $0.97(0.95-0.99)$ & 0.003 \\
\hline IADL score at baseline & $1.03(1.01-1.04)$ & $<0.001$ & & \\
\hline PSMS score at baseline & $1.06(1.03-1.09)$ & $<0.001$ & $1.04(1.01-1.08)$ & 0.009 \\
\hline Number of concomitant medications at baseline & $1.06(1.03-1.09)$ & $<0.001$ & $1.05(1.02-1.08)$ & 0.002 \\
\hline Antihypertensives/cardiac therapy & & & & \\
\hline at baseline $($ no $=0$, yes $=1)$ & $1.19(1.03-1.37)$ & 0.020 & & \\
\hline
\end{tabular}

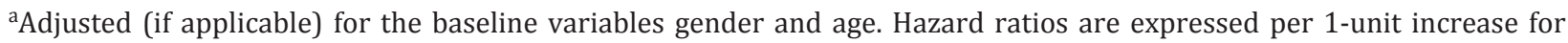
continuous variables and for the condition present for categorized variables.

years at the time of AD diagnosis. Larson et al. [13] observed a median life span of 7.5 years for untreated AD patients aged $\leq 75$ years, 4.9-5.6 years for those aged 76-85 years, and 3.2 years for those aged $>85$ years at diagnosis.

\section{Cox Regression Models}

Univariate Cox proportional hazards modeling showed that a shorter time to death after $\mathrm{AD}$ diagnosis was associated with male gender, older age, lower cognitive ability, more impaired instrumental and basic activities of daily living capacities, a greater number of concomitant medications, and antihypertensives/cardiac therapy at baseline. When subjected to multivariate backward elimination modeling, these factors were retained in the Cox model, with the exception of IADL capacity and antihypertensives/cardiac therapy. The hazard ratios (with 95\% CIs), and the p values are listed in table 4. Level of education, APOE genotype, and age at onset of AD were not significant factors in the models. However, the two variables age at the start of ChEI therapy and age at onset exhibited a strong linear association $(r=0.955$, $\mathrm{p}<0.001$ ).

\section{Discussion}

In this 15-year follow-up of $\mathrm{AD}$ patients, we found that the mean survival time \pm SD was $8.83 \pm 3.50$ years from the estimated onset of symptoms and $5.73 \pm 2.76$ years from the start of ChEI treatment, which was initiated almost immediately after the diagnosis of AD. Males had a shorter life expectancy than females. Younger individuals showed a longer life span after the baseline but exhibited a greater reduction in the length of life compared with the general population of the same age. A similar life expectancy in our ChEI-treated patients and untreated AD cohorts was observed for those diagnosed before the age of 85 years, but a longer survival time compared with untreated individuals was indicated among the oldest old ( $\geq 85$ years). Carriers of two APOE $\varepsilon 4$ alleles or patients with a higher level of education were significantly younger at death; however, no difference in life span after AD diagnosis was detected among the APOE genotypes or education levels. 
In Sweden, the expected mean length of life is 79.9 years for men and 83.5 years for women [8]. The males with AD who participated in the SATS lived 1 additional year (80.9 years), on average, whereas the participating females lived approximately 1 year less (82.4 years). In the current study of ChEI-treated patients as well as in most previous studies of untreated individuals with $\mathrm{AD}[6,7,13]$, the survival time after diagnosis was strongly dependent on age. These findings indicate a similar life expectancy after AD diagnosis between ChEI-treated and untreated patients aged up to approximately 84 years.

The treated SATS participants diagnosed at $\geq 85$ years of age exhibited a mean survival time of 5.2 years in the present study (i.e., almost 2 years longer than that reported earlier for untreated AD patients in the US) $[6,13]$. The SATS survival did not differ from the life expectancy at 85 years observed in the Swedish general population, which was similar to the life table presented in the article from the US [6]. However, the number of individuals in the oldest old AD cohorts is small. Participation in studies and variations in mortality may be more influenced by other factors among the oldest patients, such as manifestation of the disease, concomitant medical disorders, and psychiatric symptoms. Nevertheless, a recent study from our group showed a better cognitive response to ChEI therapy and a slower disease progression among older individuals with AD [19]. The oldest individuals might have a reduced cognitive reserve because of their advanced age that can lead to an earlier manifestation of the typical AD symptoms, worse performance on standardized cognitive tests, and hence earlier detection of the disease. Diagnosis and treatment might occur in a milder stage of AD, which may improve the results of interventions. Therefore, the effects of ChEI therapy might be one explanation for the longer survival time observed in the SATS group aged $\geq 85$ years.

The current study showed that $\mathrm{AD}$ patients with a higher education level performed better cognitively at the time of diagnosis but died, on average, approximately 2.5 years earlier, which supports the cognitive reserve hypothesis [29]. Individuals with a higher education level are expected to have a higher cognitive ability during their adult life and perform better on most standardized cognitive tests such as the MMSE, which normally uses a single threshold to identify patients with dementia. Therefore, it is assumed that those individuals require a relatively larger burden of $\mathrm{AD}$ pathology at the onset of clinical symptoms [30]. The brain-reserve hypothesis is supported by the observation of faster cognitive decline among patients with more years of education in several $[19,29,31]$ but not all $[32,33]$ studies. Nevertheless, most previous studies have demonstrated that the participants' level of education does not influence survival time after the onset or diagnosis of $\operatorname{AD}[6,10,13,31]$. This finding is not conclusive, as associations between lower education and increased mortality [34], as well as higher education and increased mortality [15], have been reported. The large percentage of highly educated participants in the US studies (e.g., 75\% were college graduates [6] and 70\% had at least 12 years of education [13]) indicates a measure of dispersion that might be too small to allow the detection of any significant differences. In Sweden, access to the health care system is publicly funded and not dependent on the individual's income or health insurance coverage [35], which implies that the SATS participants are more representative of the general population.

In this study, the carriers of two APOE $\varepsilon 4$ alleles were significantly younger at the onset of $\mathrm{AD}$ and the time of diagnosis, as well as, on average, approximately 3 years younger at death than were noncarriers. However, APOE genotype did not affect the length of life after diagnosis. Some studies found that the presence of at least one APOE $\varepsilon 4$ allele implied an earlier onset [36] and a faster rate of cognitive deterioration [19, 37]. However, other authors reported no difference in the onset of $\mathrm{AD}[38]$ and progression rate between $\varepsilon 4$ carriers and noncarriers [38, 39], or a faster cognitive decline in noncarriers [40]. The evidence is also mixed regarding the relationship between APOE genotype and survival time after AD diagnosis. Various studies have observed a shorter life span for $\varepsilon 4$ carriers [16], no difference [7, 
Wattmo et al.: Risk Factors That Affect Life Expectancy in Alzheimer's Disease: A 15-Year Follow-Up

14], or a shorter life expectancy for noncarriers [40]. A recent study found an association between APOE $\varepsilon 4$ carriers and higher mortality in cognitively normal individuals and in patients with $\mathrm{AD}$ but not in the mild cognitive impairment or other dementia groups [41]. Nevertheless, although the $\varepsilon 4$ carriers might have an earlier onset of AD and a more aggressive form of the disease, the impact of the $\varepsilon 4$ allele on mortality in $\mathrm{AD}$ is still unclear. In genomewide association studies, APOE has been reported as a very, if not the most, important genetic factor affecting human longevity [42, 43].

Most studies [13,14,17], including ours, have shown that more pronounced cognitive impairment predicts a shorter survival time after AD diagnosis, after adjustment for gender and age. Rountree et al. [10] found no association between disease severity at baseline and time to death; however, those authors included the variable 'preprogression rate' (calculated by using the patient's initial MMSE score and symptom duration), which became significant in their multivariate Cox model. In the present study, each 1-point decrease on the MMSE scale was related to an increased risk of death of 3\% per year. The MMSE score might serve as an independent marker of the severity of $\mathrm{AD}$, and thus might be a prognostic tool for life expectancy and for the need of care and community-based services.

The advantages of the 3-year prospective SATS are the large cohort of ChEI-treated AD outpatients with concomitant illnesses and medications from a routine clinical setting. The 14 memory clinics that participated in the SATS served different geographical regions across Sweden, urban as well as rural areas; therefore, a wide spread of individuals with varying life conditions and socioeconomic status might be assumed. The baseline in this study was the start of ChEI treatment, which occurred shortly after the diagnosis of the disease. This measurement point had the advantage of not relying on self-reports and/or informant reports of the patient's age at the onset of symptoms, which is usually estimated retrospectively in clinical cohorts such as the SATS. Typically, AD has an insidious and gradual onset and could sometimes be difficult to distinguish from an age-related decline at the start of the disease [13]. The time of diagnosis is a clinically relevant moment, at which the symptoms have reached a certain level (i.e., they are severe enough to affect the individual's life situation and the ability to manage independently in society). Therefore, medical care has been sought at this point.

The limitations of this study and other reports of prevalent AD are that survival might have been overestimated (survivorship bias) when individuals with a fast-progressing disease were not identified before death or were too ill to participate in the study and thus were not enrolled. In contrast, underestimation of the years of life lost might have occurred, as life tables included AD cases in the population. Comorbid medical $[13,44]$ and psychiatric conditions [45] might increase mortality in dementia; these variables were not specifically addressed in this study. However, not all previous studies have observed this association [10].

A detailed investigation of the survival time of patients treated with ChEIs is essential for the evaluation of the influence of future disease-modifying therapies on mortality in AD. The tables presented in the current study can be used as a tool to estimate life expectancy for individuals with different demographic and clinical characteristics. The few AD studies that have analyzed the relationship between ChEI treatment and survival have reported conflicting results regarding whether these drugs increase the length of life $[9,10]$. Mortality studies performed in ChEI-treated participants are warranted to expand the knowledge on the potential influence of these drugs on life expectancy and consequently on the costs of dementia care. Furthermore, if ChEI therapy prolongs life in the oldest old AD patients, the individuals' quality of life and the caregiver burden during this time need to be evaluated. This information is of great importance for the health care system and for society as well as for clinicians and the patients and their families. 
In conclusion, the current study of ChEI-treated patients showed that a diagnosis of AD implies on average 5-6 years of remaining disabled life, which is consistent with that reported in previous studies of untreated AD patients. The number of 'lost years' compared with the general population ranged from 15.0/17.6 for males/females diagnosed before 65 years of age to 0 for individuals diagnosed at 85 years of age or older. A longer survival time was observed among our oldest age group compared with earlier studies of untreated individuals with $\mathrm{AD}$, which raises the question of whether this outcome reflects a positive response to ChEI therapy. The mild AD cohort had significantly less reduction in their life span compared with those in the moderate disease stage, which emphasizes the importance of early diagnosis and treatment. A higher level of education or the presence of two APOE $\varepsilon 4$ alleles might be risk factors in $\mathrm{AD}$ regarding faster disease progression and an earlier death.

\section{Acknowledgments}

We wish to thank all SATS patients and their relatives for their cooperation in this study. The authors are grateful to Tomas Johansson, Statistics Sweden, for help with obtaining the life tables, and to the staff at the Swedish population register (Swedish Tax Agency) for administrative help. We also wish to thank the staff from all different centers that took part in the management of the patients and provided administrative support to the study.

\section{Disclosure Statement}

C.W. received an ALF Young Researcher Grant from the Region Skåne, Sweden. E.L. received grant No. 523-2010-520 from the Swedish Research Council. The sponsors had no involvement in the study design, in the collection, analysis, and interpretation of data, in the writing of the report, or in the decision to submit the manuscript.

C.W. received speaker honoraria from Novartis. E.L. received speaker honoraria from Lundbeck Inc. and Novartis. L.M. has no disclosures to report.

\section{References}

1 Fratiglioni L, De Ronchi D, Aguero-Torres H: Worldwide prevalence and incidence of dementia. Drugs Aging 1999;15:365-375.

-2 Wortmann M: Dementia: a global health priority - highlights from an ADI and World Health Organization report. Alzheimers Res Ther 2012;4:40.

3 Alzheimer's Disease International: World Alzheimer Report 2010. The Global Economic Impact of Dementia; in Wimo A, Prince M (eds). London, 2010, pp 1-56.

-4 Ott A, Breteler MM, van Harskamp F, Claus JJ, van der Cammen TJ, Grobbee DE, Hofman A: Prevalence of Alzheimer's disease and vascular dementia: association with education. The Rotterdam study. BMJ 1995;310: 970-973.

5 Galasko D, Edland SD, Morris JC, Clark C, Mohs R, Koss E: The Consortium to Establish a Registry for Alzheimer's Disease (CERAD). Part XI. Clinical milestones in patients with Alzheimer's disease followed over 3 years. Neurology 1995;45:1451-1455.

6 Brookmeyer R, Corrada MM, Curriero FC, Kawas C: Survival following a diagnosis of Alzheimer disease. Arch Neurol 2002;59:1764-1767.

-7 Helzner EP, Scarmeas N, Cosentino S, Tang MX, Schupf N, Stern Y: Survival in Alzheimer disease: a multiethnic, population-based study of incident cases. Neurology 2008;71:1489-1495.

8 Statistiska centralbyrån, Sverige (Statistics Sweden): Life tables 2008-2012. http://www.scb.se/Pages/ ProductTables_25809.aspx (accessed July 22, 2013).

-9 Gasper MC, Ott BR, Lapane KL: Is donepezil therapy associated with reduced mortality in nursing home residents with dementia? Am J Geriatr Pharmacother 2005;3:1-7.

10 Rountree SD, Chan W, Pavlik VN, Darby EJ, Doody RS: Factors that influence survival in a probable Alzheimer disease cohort. Alzheimers Res Ther 2012;4:16.

11 Brodaty H, Seeher K, Gibson L: Dementia time to death: a systematic literature review on survival time and years of life lost in people with dementia. Int Psychogeriatr 2012;24:1034-1045. 
Wattmo et al.: Risk Factors That Affect Life Expectancy in Alzheimer's Disease: A 15-Year Follow-Up

12 Barclay LL, Zemcov A, Blass JP, McDowell FH: Factors associated with duration of survival in Alzheimer's disease. Biol Psychiatry 1985;20:86-93.

13 Larson EB, Shadlen MF, Wang L, McCormick WC, Bowen JD, Teri L, Kukull WA: Survival after initial diagnosis of Alzheimer disease. Ann Intern Med 2004;140:501-509.

14 Bonsignore M, Heun R: Mortality in Alzheimer's disease. Dement Geriatr Cogn Disord 2003;15:231-236.

15 Stern Y, Tang MX, Denaro J, Mayeux R: Increased risk of mortality in Alzheimer's disease patients with more advanced educational and occupational attainment. Ann Neurol 1995;37:590-595.

16 Tilvis RS, Strandberg TE, Juva K: Apolipoprotein E phenotypes, dementia and mortality in a prospective population sample. J Am Geriatr Soc 1998;46:712-715.

17 Walsh JS, Welch HG, Larson EB: Survival of outpatients with Alzheimer-type dementia. Ann Intern Med 1990; 113:429-434.

18 Wallin AK, Andreasen N, Eriksson S, Batsman S, Nasman B, Ekdahl A, Kilander L, Grut M, Ryden M, Wallin A, Jonsson M, Olofsson H, Londos E, Wattmo C, Eriksdotter Jonhagen M, Minthon L: Donepezil in Alzheimer's disease: what to expect after 3 years of treatment in a routine clinical setting. Dement Geriatr Cogn Disord 2007;23:150-160.

19 Wattmo C, Wallin AK, Londos E, Minthon L: Predictors of long-term cognitive outcome in Alzheimer's disease. Alzheimers Res Ther 2011;3:23.

20 Wattmo C, Hansson 0, Wallin AK, Londos E, Minthon L: Predicting long-term cognitive outcome with new regression models in donepezil-treated Alzheimer patients in a naturalistic setting. Dement Geriatr Cogn Disord 2008;26:203-211.

-21 Wattmo C, Wallin AK, Londos E, Minthon L: Risk factors for nursing home placement in Alzheimer's disease: a longitudinal study of cognition, ADL, service utilization, and cholinesterase inhibitor treatment. Gerontologist 2011;51:17-27.

-22 Folstein MF, Folstein SE, McHugh PR: 'Mini-mental state'. A practical method for grading the cognitive state of patients for the clinician. J Psychiatr Res 1975;12:189-198.

23 Frances A, American Psychiatric Association: Diagnostic and statistical manual of mental disorders: DSM-IV: prepared by the Task Force on DSM-IV, ed 4. Washington, American Psychiatric Association, 1994.

24 McKhann G, Drachman D, Folstein M, Katzman R, Price D, Stadlan EM: Clinical diagnosis of Alzheimer's disease: report of the NINCDS-ADRDA Work Group under the auspices of Department of Health and Human Services Task Force on Alzheimer's Disease. Neurology 1984;34:939-944.

25 Lawton MP, Brody EM: Assessment of older people: self-maintaining and instrumental activities of daily living. Gerontologist 1969;9:179-186.

26 Statistiska centralbyrån, Sverige (Statistics Sweden): Statistisk årsbok för Sverige 1999 (Statistical Yearbook of Sweden 1999). Stockholm, 1999.

27 Statistiska centralbyrån, Sverige (Statistics Sweden): Statistisk årsbok för Sverige 2004 (Statistical Yearbook of Sweden 2004). Stockholm, 2004.

28 Statistiska centralbyrån, Sverige (Statistics Sweden): Statistisk årsbok för Sverige 2009 (Statistical Yearbook of Sweden 2009). Stockholm, 2009.

29 Stern Y, Albert S, Tang MX, Tsai WY: Rate of memory decline in AD is related to education and occupation: cognitive reserve? Neurology 1999;53:1942-1947.

-30 Bennett DA, Wilson RS, Schneider JA, Evans DA, Mendes de Leon CF, Arnold SE, Barnes LL, Bienias JL: Education modifies the relation of AD pathology to level of cognitive function in older persons. Neurology 2003;60: 1909-1915.

-31 Bruandet A, Richard F, Bombois S, Maurage CA, Masse I, Amouyel P, Pasquier F: Cognitive decline and survival in Alzheimer's disease according to education level. Dement Geriatr Cogn Disord 2008;25:74-80.

-32 Mortimer JA, Ebbitt B, Jun SP, Finch MD: Predictors of cognitive and functional progression in patients with probable Alzheimer's disease. Neurology 1992;42:1689-1696.

-33 Atri A, Shaughnessy LW, Locascio JJ, Growdon JH: Long-term course and effectiveness of combination therapy in Alzheimer disease. Alzheimer Dis Assoc Disord 2008;22:209-221.

-34 Aguero-Torres H, Fratiglioni L, Guo Z, Viitanen M, Winblad B: Prognostic factors in very old demented adults: a seven-year follow-up from a population-based survey in Stockholm. J Am Geriatr Soc 1998;46:444-452.

-35 Lagergren M: The systems of care for frail elderly persons: the case of Sweden. Aging Clin Exp Res 2002;14: 252-257.

36 Meyer MR, Tschanz JT, Norton MC, Welsh-Bohmer KA, Steffens DC, Wyse BW, Breitner JC: APOE genotype predicts when-not whether-one is predisposed to develop Alzheimer disease. Nat Genet 1998;19:321-322.

-37 Craft S, Teri L, Edland SD, Kukull WA, Schellenberg G, McCormick WC, Bowen JD, Larson EB: Accelerated decline in apolipoprotein E-epsilon4 homozygotes with Alzheimer's disease. Neurology 1998;51:149-153.

-38 Kleiman T, Zdanys K, Black B, Rightmer T, Grey M, Garman K, Macavoy M, Gelernter J, van Dyck C: Apolipoprotein E epsilon4 allele is unrelated to cognitive or functional decline in Alzheimer's disease: retrospective and prospective analysis. Dement Geriatr Cogn Disord 2006;22:73-82.

39 Rasmusson DX, Carson KA, Brookmeyer R, Kawas C, Brandt J: Predicting rate of cognitive decline in probable Alzheimer's disease. Brain Cogn 1996;31:133-147.

40 Stern Y, Brandt J, Albert M, Jacobs DM, Liu X, Bell K, Marder K, Sano M, Albert S, Del-Castillo Castenada C, Bylsma F, Tycko B, Mayeux R: The absence of an apolipoprotein epsilon4 allele is associated with a more aggressive form of Alzheimer's disease. Ann Neurol 1997;41:615-620. 
-41 Beydoun MA, Beydoun HA, Kaufman JS, An Y, Resnick SM, O’Brien R, Ferrucci L, Zonderman AB: Apolipoprotein E epsilon4 allele interacts with sex and cognitive status to influence all-cause and cause-specific mortality in US older adults. J Am Geriatr Soc 2013;61:525-534.

-42 Deelen J, Beekman M, Uh HW, Helmer Q, Kuningas M, Christiansen L, Kremer D, van der Breggen R, Suchiman HE, Lakenberg N, van den Akker EB, Passtoors WM, Tiemeier H, van Heemst D, de Craen AJ, Rivadeneira F, de Geus EJ, Perola M, van der Ouderaa FJ, Gunn DA, Boomsma DI, Uitterlinden AG, Christensen K, van Duijn CM, Heijmans BT, Houwing-Duistermaat JJ, Westendorp RG, Slagboom PE: Genome-wide association study identifies a single major locus contributing to survival into old age; the APOE locus revisited. Aging Cell 2011;10: 686-698.

-43 Nebel A, Kleindorp R, Caliebe A, Nothnagel M, Blanche H, Junge O, Wittig M, Ellinghaus D, Flachsbart F, Wichmann HE, Meitinger T, Nikolaus S, Franke A, Krawczak M, Lathrop M, Schreiber S: A genome-wide association study confirms APOE as the major gene influencing survival in long-lived individuals. Mech Ageing Dev 2011;132:324-330.

44 Helmer C, Joly P, Letenneur L, Commenges D, Dartigues JF: Mortality with dementia: results from a French prospective community-based cohort. Am J Epidemiol 2001;154:642-648.

45 Scarmeas N, Brandt J, Albert M, Hadjigeorgiou G, Papadimitriou A, Dubois B, Sarazin M, Devanand D, Honig L, Marder K, Bell K, Wegesin D, Blacker D, Stern Y: Delusions and hallucinations are associated with worse outcome in Alzheimer disease. Arch Neurol 2005;62:1601-1608. 